\author{
Military Technical College \\ Kobry Elkobbah, \\ Cairo, Egypt \\ May $16-18,2006$
}

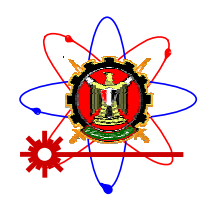

$3^{\text {nd }}$ International Conference on

Engineering Mathematics and

Physics (ICMEP-3)

\title{
MODELLING AND SIMULATION IN DECISION MAKING PROCESSES
}

\author{
JURCAK ${ }^{1}$ VOJTECH, BUCKA ${ }^{2}$ PAVEL, GEREC ${ }^{3}$ PETER, DUBOVSKA ${ }^{4}$ LUBOMIRA
}

\begin{abstract}
Time is a limiting factor, which influences the decision making process. To reduce this factor, it is very important to use all means, which are currently available.

Using the modern computer technology in dealing with this kind of decision making problems help to reduce the time, this is needed to complete the whole decision making process.

This article deals with the application of modeling and simulation resources in the area of Air Defense battle. There are introduced some projects, which are being used in modeling and simulation processes in the area of Air Defense and which were created at the Air Defense Department.

The software product ,RADAR'S FIELD, was created to evaluate the direct and also the radiolocation visibility in the 360 -degree area.

To create the battle formations of ground Air Defense equipment there is used a software product, OPTIMALIZATION ,.

In the article are also introduced those conditions and methods, witch were being used in the process of creating the model of Air Defense battle in software product , AIR DEFENSE BATTLE SIMULATION,.

This software product enlarges the possibilities of commanders and staff decision-making process. The result of this software product provides the necessary data for the commander's decision. This decision must be carried out according to general analysis of a specific situation.
\end{abstract}

\section{KEY WORDS}

Command, Control, Planning, Decision - Making Process, Air Defense, Electronic Warfare, Reconnaissance, Fire Control System, Firing System, Object, Model, Subject, Optimization, Switch of Fire, Engagement Zone, Firing Cycle.

\footnotetext{
${ }^{1}$ Professor, Dpt. of Electronic ,PhD., the Academy of the Armed Forces, Liptovsky Mikulas, Slovakia

${ }_{2}^{2}$ Associate professor, Dpt. of Electronic, PhD., the Academy of the Armed Forces, Liptovsky Mikulas, Slovakia

${ }^{3}$ Captain, Dpt. of Electronic, PhD., the Academy of the Armed Forces, Liptovsky Mikulas, Slovakia

${ }^{4}$ Doctor of Natural Sciences, the Academy of the Armed Forces, Liptovsky Mikulas, Slovakia
} 


\section{MODELLING AND SIMULATION IN DECISION MAKING PROCESSES}

Time is a limiting factor, which influences the decision making process. To reduce this factor, it is very important for the staff to use all means, which are currently available.

Using the modern computer technology in dealing with this kind of decision - making problems helps to reduce the time, which is needed to complete the whole decision -making process. Time is a dominant factor in selecting the right kind of decision making process.

In the area of the Air Forces and Air Defence Forces of the Slovak Republic, there is possible to use many various software products, which were created by the Air Defence Department at the Armed Forces Academy in Liptovsky Mikulas. In praxis, military exercises and complex staff trainings there is being used a project, called ,POLE, Fig 1, Fig 2. To create the optimal mixed battle and formation is used a project called,OPTIMALIZATION, Fig. 4 - Fig. 7.

Both projects were created by the Air Defence Department as a part of science research.

The project ,POLE, was created to evaluate the direct and also the radiolocation visibility in the 360 - degree area. In this project, we can specify the type of the radar station and the altitude of an aircraft. Following the results, there is a possibility to create a continual radiolocation-field statement according to simulated system of reconnaissance and all of his advantages and disadvantages.

To create the battle formations of Ground Air Defence equipment there is used a project, OPTIMALIZATION,. This project, as well as the project, POLE, uses some terrain information, which are obtained from the Digital Model of Terrain of the Slovak Republic and some neighbour states - Fig. 3. The project was created according to need of creating the Ground Air Defence battle formations and their optimal deployment in the battlefield. The main algorithm includes basic principles, which are also used in the tactics of fire units. Of course there are mathematical relations that enable to detect radiolocation ranges in specified flight approach.

The system is able to propose the best position of specific battle element and the location of Headquarters according to calculated:

1. The mean detection value.

2. The engagement area.

3. The distance of continuous air target.

4. The number of fires from positions.

This analyse of created battle formation is necessary to execute by considering the expected enemy strike.

This analyse is possible to execute by:

1. Realizing the Air Defence battle in specified terrain - what seems to be, due to economic and material unreal (only some of its fragments are realized).

2. The simulation (using the PCs) by using of Air Defence Battle Model.

\section{The Air Defence Battle Model Requirements}

The Air Defence Battle Model represents mental or material system, which is able to reflect, express, present, imitate, simulate - in one word, to substitute the real battle process of active Air Defence and enemy equipments, in conjunction with partial objects, processes, various aspects, parts, elements, relations and functions.

It is necessary to create the whole model in such kind of way that would enable: 
1. Obtain new information about the Air Defence battle elements and relations for purpose of prediction.

2. Execute the practical tasks, but first of all, exercise and train own forces (their skills, ability, etc.).

3. Provide economical, tactical and others results.

This kind of a complex model is not available in the present time. The Air Defence battle analysis can be performed by using the mathematical-analytic models. Presented models do not involve explicit time parameters - they have stochastic or deterministic character. These models are usually solved for computers. Here belong mostly some application programs, power ratio, battle possibilities, casualty prognostics, optimal force distribution, etc.

Their disadvantage is the measurement uncertainty, which is caused by using the coefficients of battle progress probability. Next disadvantage is that the models aren,t realized in time and place, they aren,t dynamic. But the dynamics is very important in evaluating the factors, which influence the progress and results of model. For example the need for maneuver with forces and devices, protection of important areas, the maneuver effect, etc.

It follows, that it was important to create such kind of model, which eliminates mentioned disadvantages. This new kind of model enables simple input of entry data and new tactical and technical data, fluctuation of own forces solutions, creation of research and development experiments.

\section{The Air Defence Battle Simulation ,SimBo PVO,}

The main purpose of modelling is in course prognostics and battle results, in use of the various courses of enemy strikes. To ensure the battle results was at the Air Defence Department created the program named Air Defence Battle Simulation (SimBoPVO). This program enlarges the possibilities of commanders and staff decision - making process. The result of Air Defence Battle Simulation provides the necessary data for the commander,s decisions. This decision must be carried out according to general analysis of a specific situation.

The program allows evaluating the selected course of action of the Air Defence equipment according to possibilities of enemy destruction simulations. Each of the prepared courses of action brings general information about situation and equipment status of both fighting members. In the simulation model is also included a terrain effect and so are reached better results.

The battle simulation is performed on the Digital Model of Terrain of the Slovak Republic and some neighbour states in area of $1000 \mathrm{~km} \times 600 \mathrm{~km}$, the smallest point with the size of 1 km x 1 km Fig. 3.

There are created these models when software is running Fig. 8.

1. The Ground Air Defence equipment.

2. The Reconnaissance equipment.

3. Defended objects.

4. The Air Attack Enemy equipment.

In this program is possible to create and place battle formations of fighting parties. In addition we can execute the simulation of battle process in the real time, where are simulated the activity of own and enemy forces, according to battle progress. 
During the simulation is possible to lead the battle process in conditions without or with jamming. Fire direction control is able to execute centralized or decentralized, target assignment can be automatic or manual. Destroy the target is able to execute by single or by two missiles.

When the simulation is over, the battle process is evaluated in form of graphs and tables Fig. 9, Fig. 10. Then it is possible to choose the best course of action, according to required mission accomplishment.

This model brings for the commander enough information, which is important for optimal consideration of selected courses of action. Using this program, the commander can gather information about weak and strong areas of the fighting parties and their ground Air Defence equipments, radiolocation and direct visibility, probable enemy's strike courses, etc.

From the tables and graphs is possible to obtain mathematical evaluation of each course of action. Commander also receives information about actual status of each defended object. 


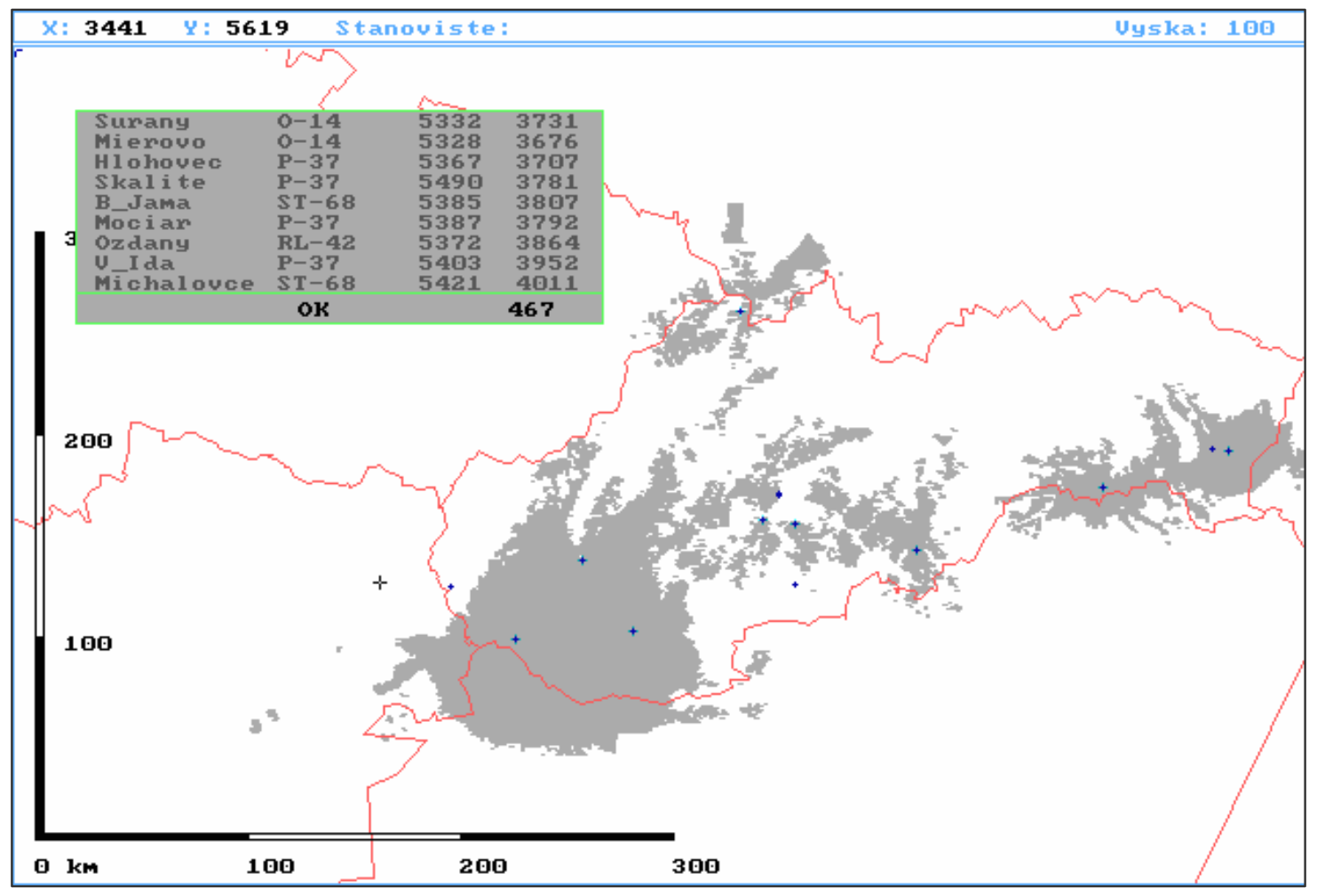

Fig.1. Radar,s field - Altitude 100m 


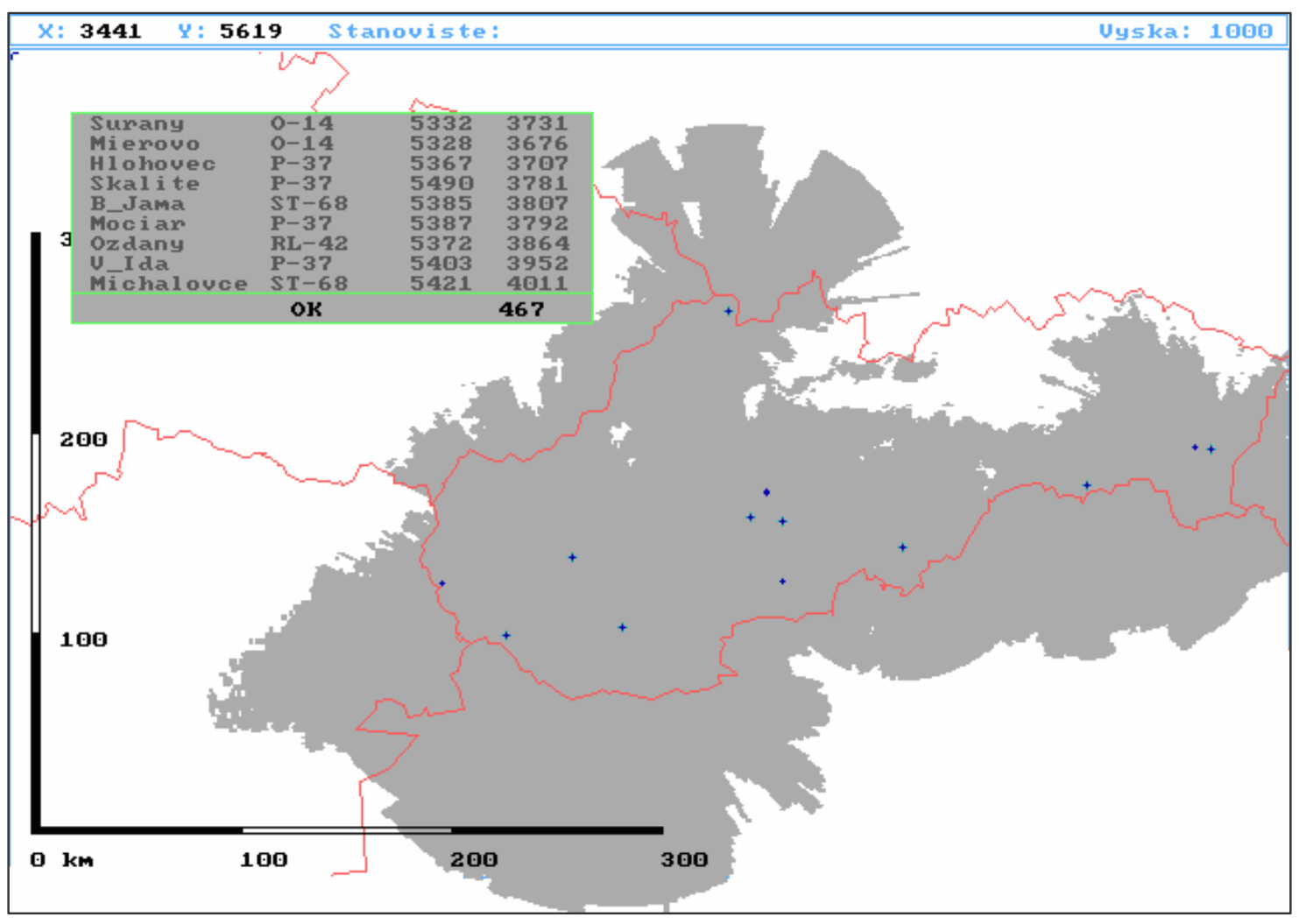

Fig.2. Radar's field - Altitude 1000m 


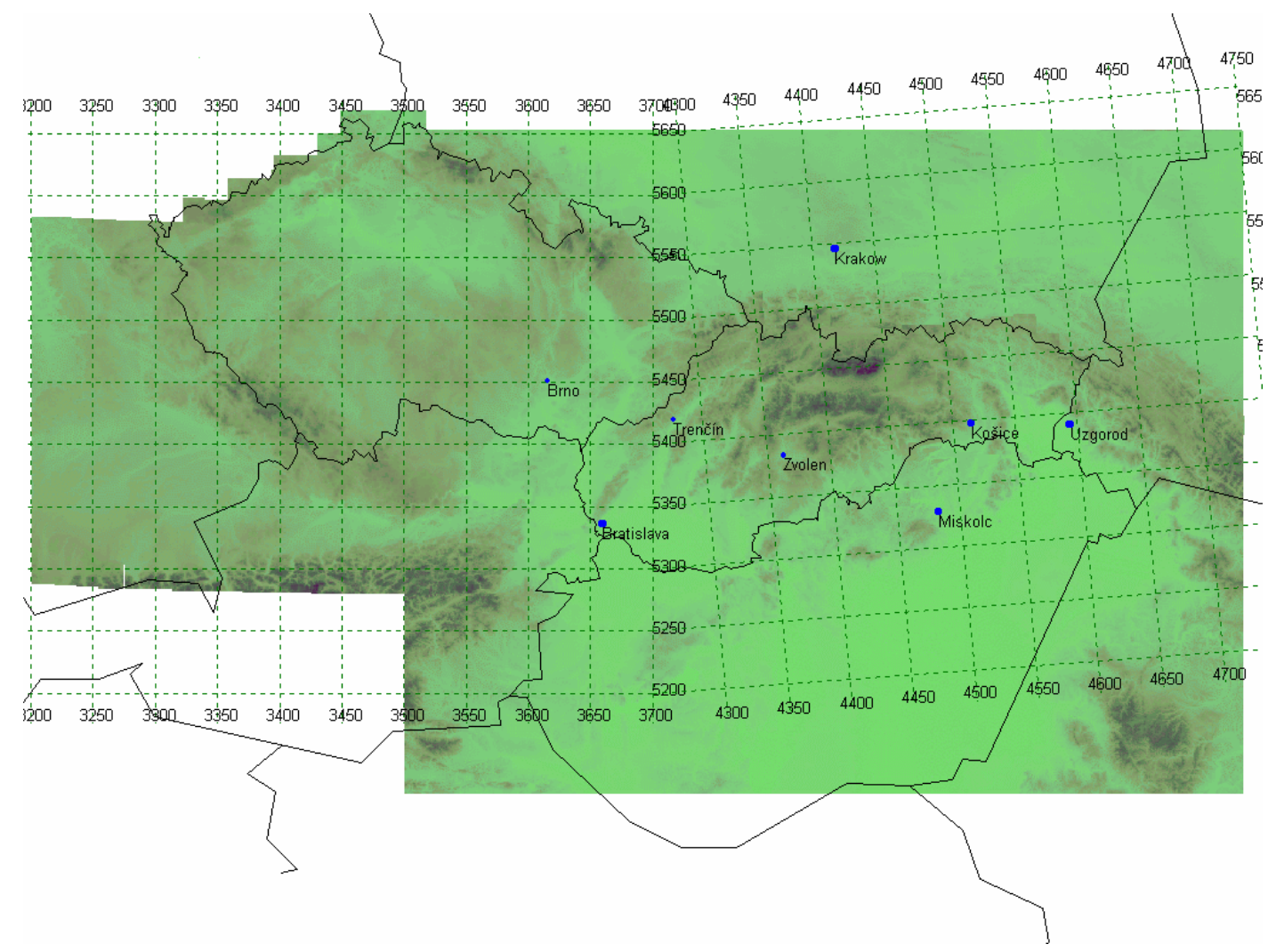

Fig.3. The digital model of terrain of the Slovak Republic and some neighbour states 


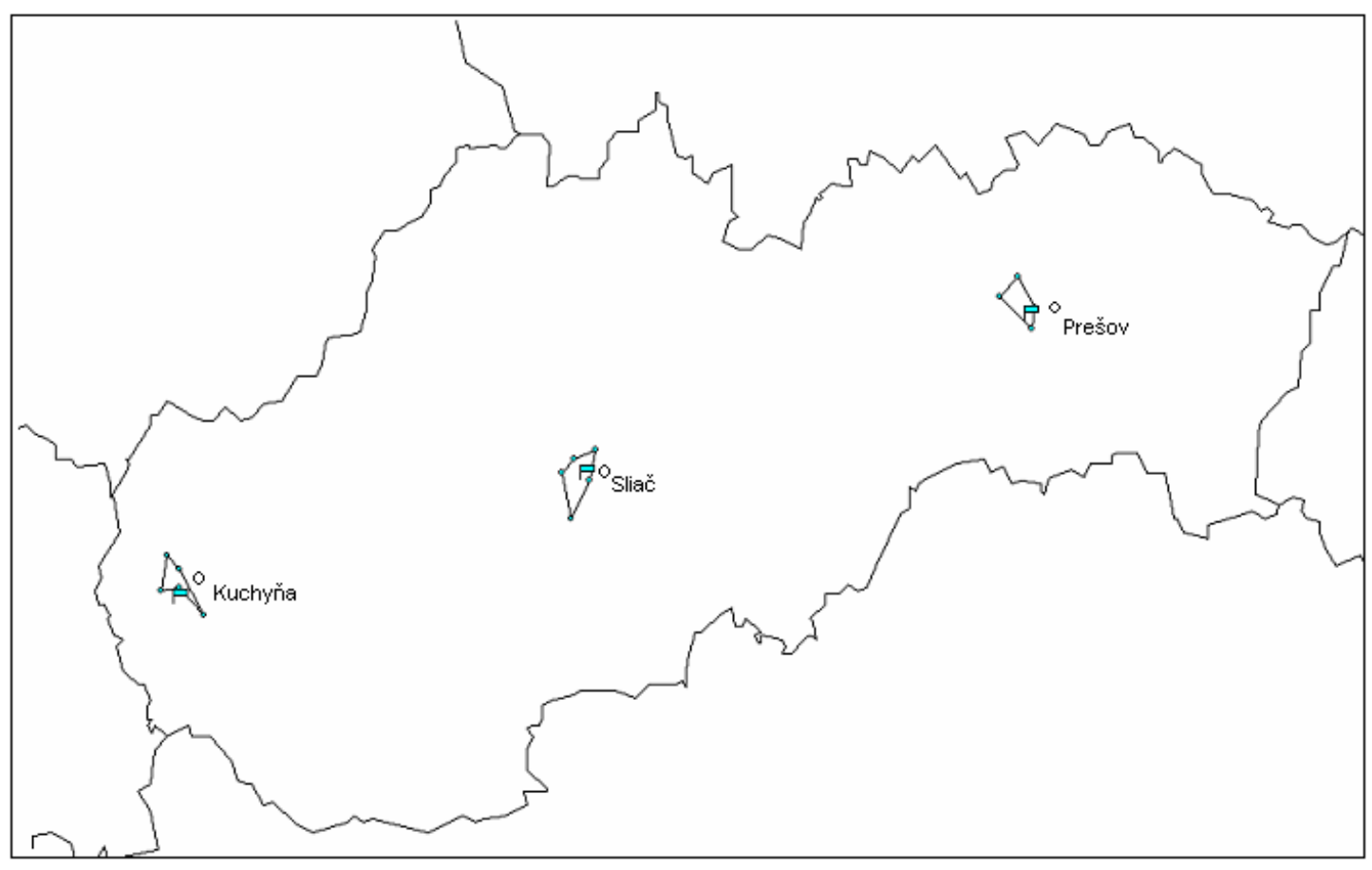

Fig.4. The combat position - Air Defence Systems - SA-6 


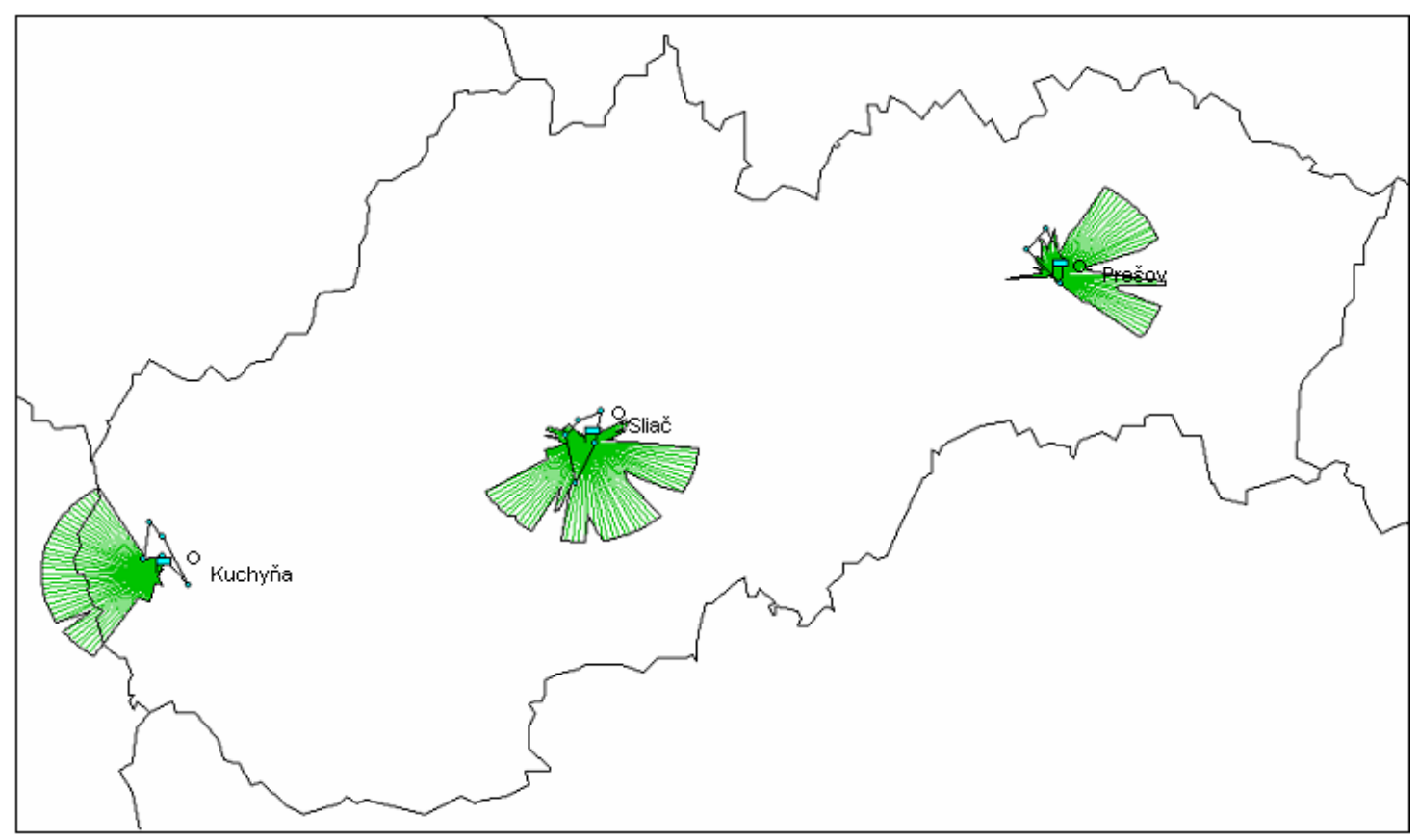

Fig.5. Air Defence Systems - SA-6 the radar,s range for: target altitude - 100m, target speed $-300 \mathrm{~m}^{-1}$ 


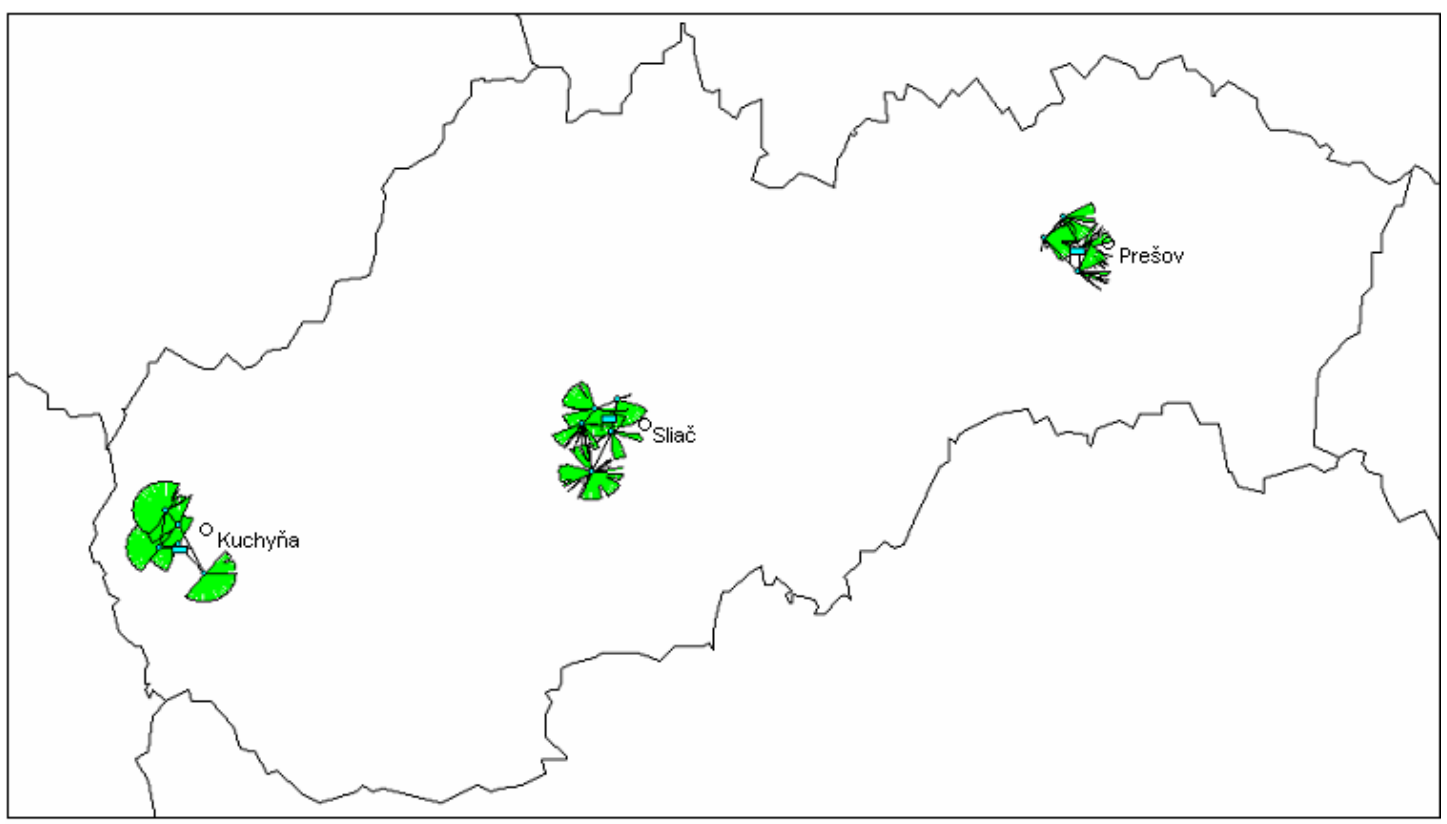

Fig.6. Air Defence Systems - SA-6, the engagement zone for: target altitude - 100m, target speed $-300 \mathrm{~m}^{-1}$ 


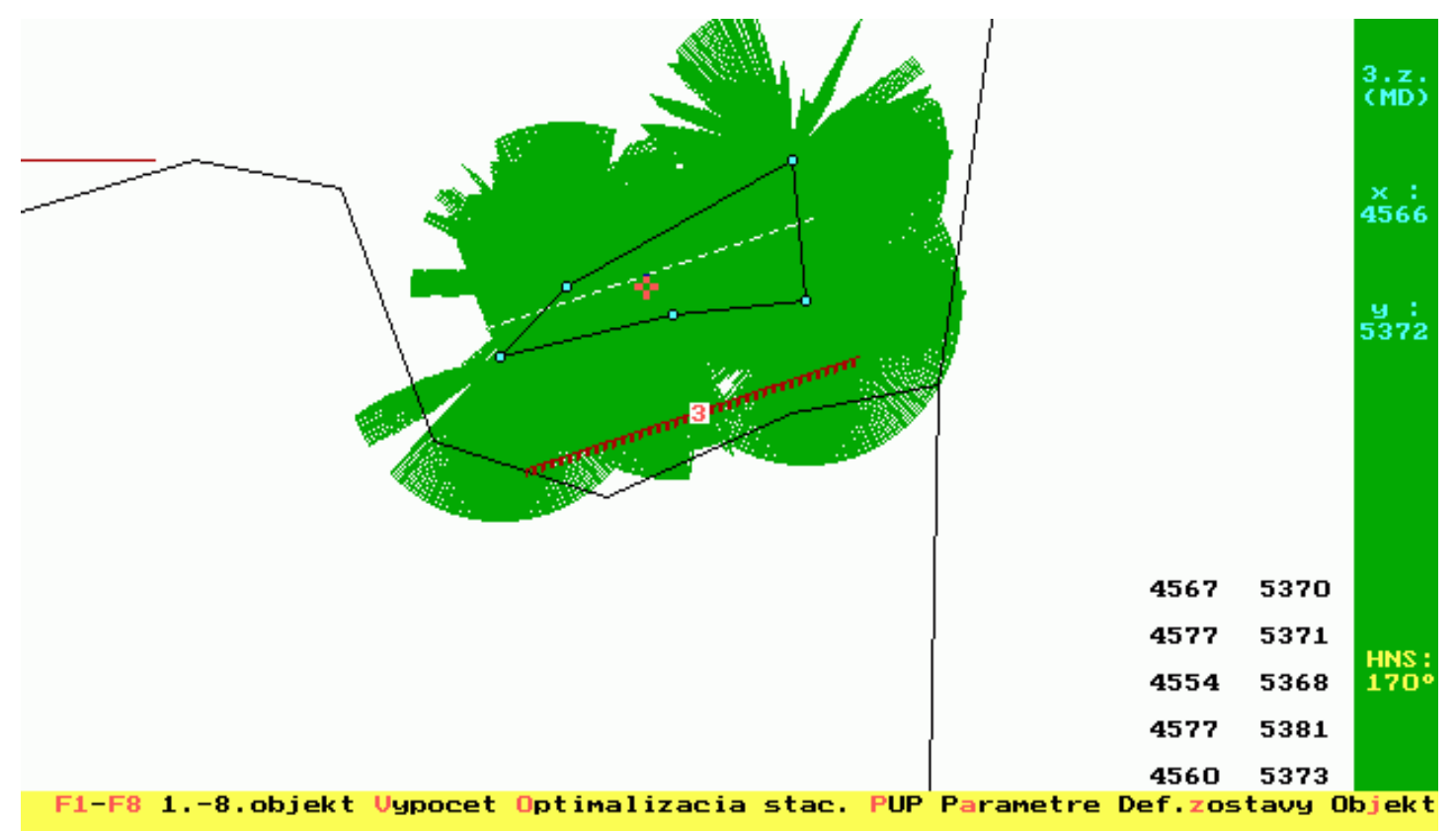

Fig.7. The surround of project,OPTIMALIZATION, Air Defence Systems - SA-6 


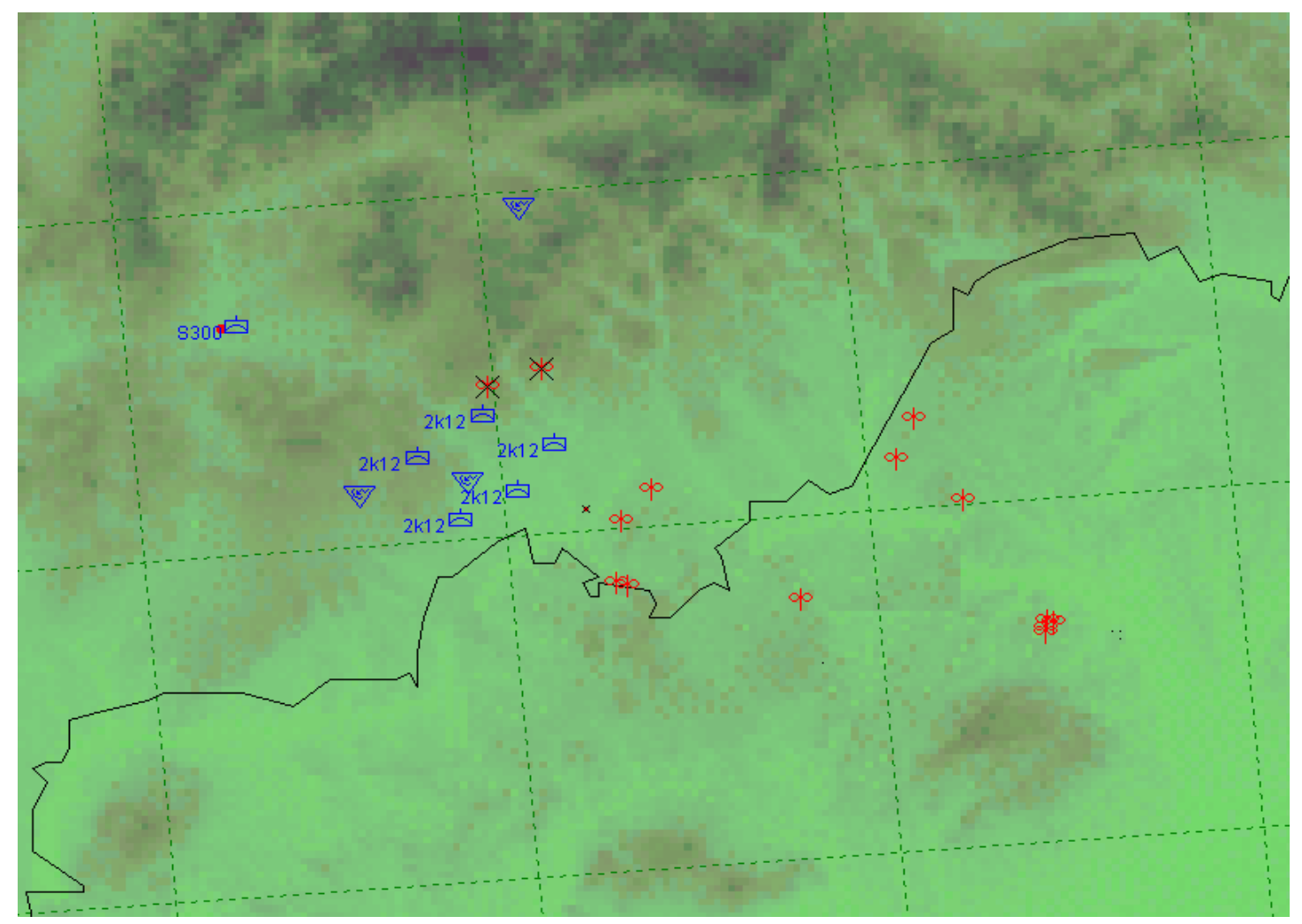

Fig. 8 Models of ground air defence, reconnaissance, air attack enemy equipment 


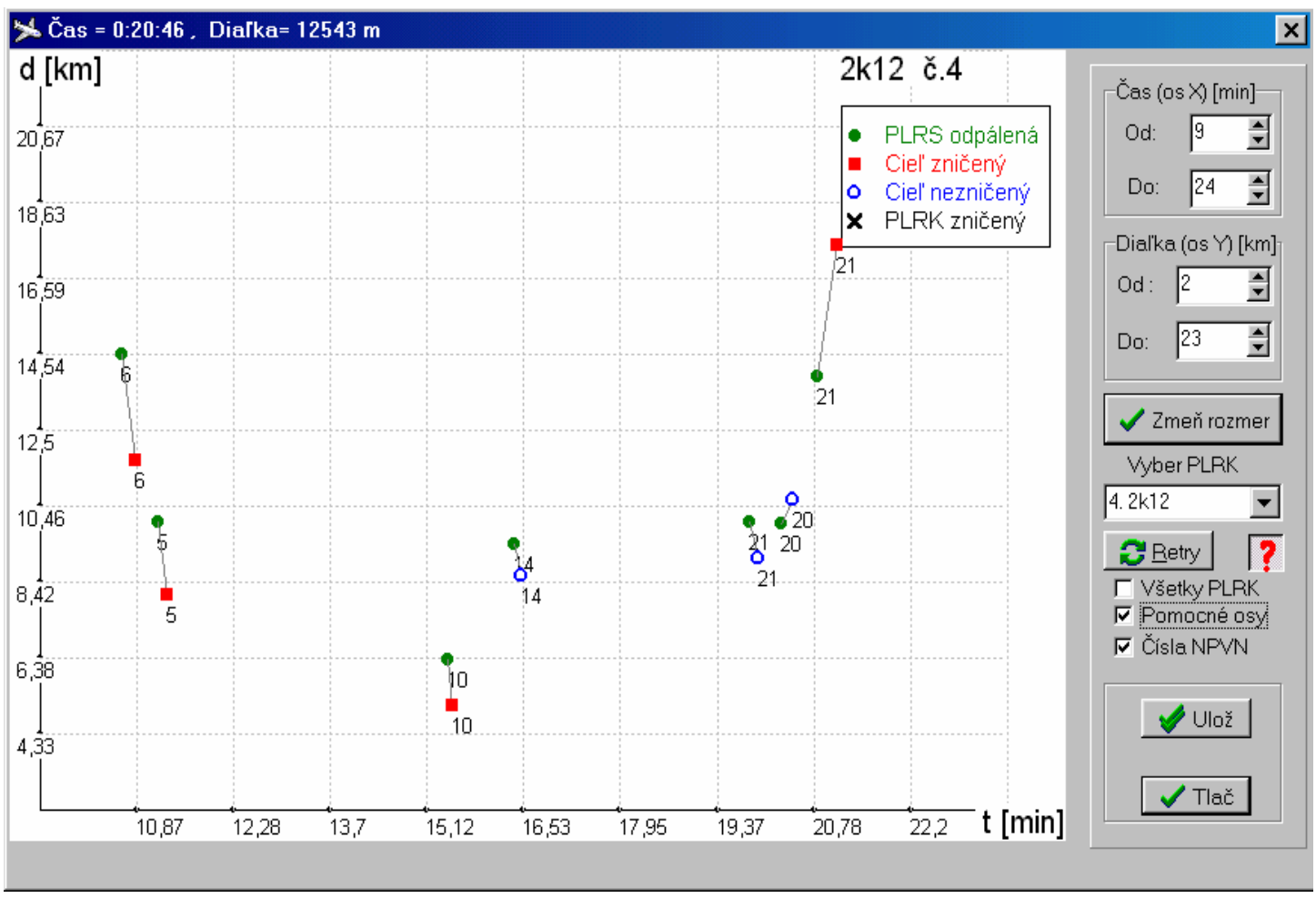

Fig.9. The battle process evaluated in form of graphs 


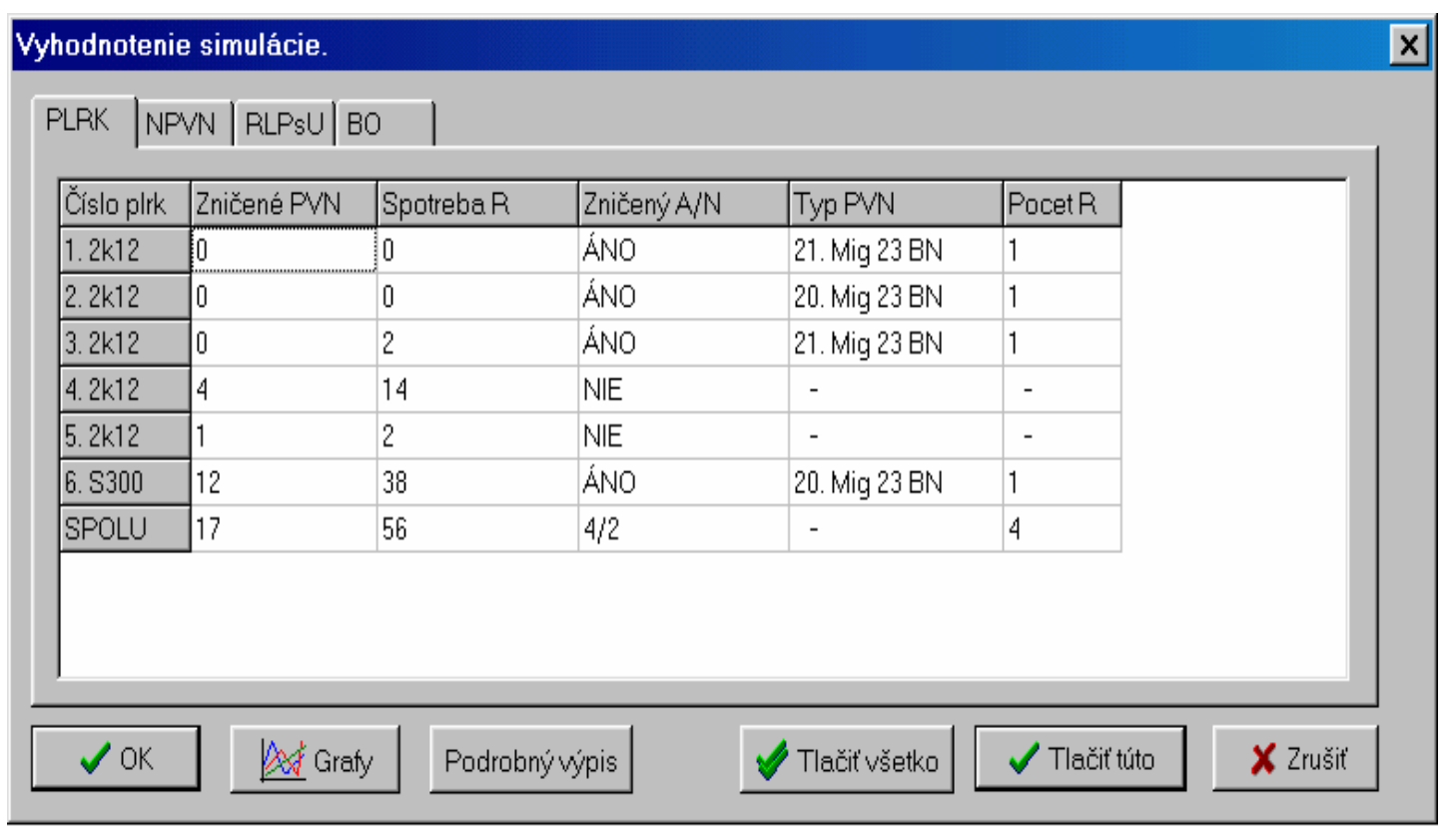

Fig.10. The battle process evaluated in form of tables 